\title{
Diversity Explosion: \\ How New Racial Demographics are Remaking America
}

\author{
by William Frey \\ Washington: Brookings Institution Press, 2015 \\ ISBN: 978-0-81572-398-1 \\ Softcover, $\$ 29.95,224$ pp.
}

\author{
Reviewed by Alain Bélanger \\ Institut national de la recherche scientifique, Montreal
}

William Frey is a well-known demographer, with almost four decades of experience studying immigration, internal migrations, and racial composition at different geographic scales in the United States. He is definitely well-positioned to describe the recent changes in the racial make-up of the USA, and to analyze the immediate and future implications brought by the "explosive growth of new racial minorities"-Hispanics, of course, but Asians and multiracial persons as well.

Diversity Explosion is written for a large audience. Specialists will nevertheless appreciate the remarkable effort made at synthesis. According to the author, most people are aware of this ethnic growth-after all, it is visible in most metropolitan areas, including their suburbs-but a few can adequately figure out its scale. Frey's goal is to communicate the magnitude of the new racial demographic shift and its potential to the common layman. This goal is successfully achieved, thanks to the effective prose of the author and the abundance of tables, figures, and maps that richly illustrate the book.

By way of introduction, the first chapter presents an overview of the long-term changes (19702050) in racial composition of the USA. It also sets the stage for the rest of the book, by presenting the different population groups that will be under focus and the geographical typology used to describe their spatial diffusion. An emphasis is put on four different groups: Hispanics, the largest minority group, which is still rapidly growing; Asians, a more recent minority but an even faster-growing group; Blacks, the traditional minority group, whose growth is slower due to less net migration; and finally, the aging, almost stagnant, and soon declining white population.

The second chapter compares the age structures of the different population groups, and describes the emerging cultural generation gap. In this chapter, the author discusses the paradoxical schools of thought on how to address the issue of the aging white baby-boomer population and the coming ethnically diverse new generations. While the older generations favour smaller government, less taxes, and fewer social support programs, the younger tend to support increased government spending on education, health, and social welfare. The penultimate chapter of the book returns to a consideration of the divergent views and focuses on the importance of minority votes on recent 
(and forthcoming) presidential campaigns. Chapter 3 takes a spatial perspective and illustrates the American racial geographic spatial patterns using several colour maps.

The core of the book (chapters 4 to 7 ) is very descriptive. Each of the chapters focuses on one of the four population groups. The chapters on Hispanics and Asians follow similar narrative structure, presenting the different countries of origin of the studied population, a socio-demographic profile contrasted to the white population's profile, and a brief spatial analysis. The chapter dedicated to the black population takes another approach and focuses on their internal migration patterns. It shows that although there are important moves from the Rusted Belt states to the New Sun Belt states, the migration is highly selective of the most educated. Chapter 7 reports on the white population, thoroughly describing the internal migration patterns while contrasting the new white flight with the earlier one. The white flight that occurred in the 1950s and 1960s is defined as white families moving from central cities to mushrooming suburbs, and the new white flight involves moves to newer and smaller areas of more distant outer suburbs and exurbs. At the macro scale, the new white flight is characterized by North-to-South moves. Due to low natural increase and low net international migration, the internal migration is almost a zero-sum game for the white population; the growth in attractive regions is contingent to population declines in less attractive regions.

Chapters 8 and 9 take a different geographic scale and look at the mobility between cities and suburbs, as well as at neighborhood segregation. It demonstrates that new minorities, particularly Hispanics, now dominate city and suburban growth in the largest metropolitan areas. Yet, whites still constitute the majority in the suburbs of the top 100 largest metropolitan areas, but minorities have been the majority in their central cities since the 2000 Census. In the Melting Pot areas (where large number of new immigrants are landing), there is evidence that neighborhood racial segregation is declining, perhaps because the new minorities are not as stigmatized as Afro-Americans. Although black/white neighbourhood segregation is also generally declining, the pace of this decline has been very slow since 1990, particularly in less attractive northern cities such as Milwaukee, Cleveland, or Detroit. In these areas, demographic inertia and aging in place conjugate with the new black flight, and outmigration of its better-educated segments to the New Sun Belt, to maintain a concentration of black children in high-poverty areas. Furthermore, Hispanic and Asian segregation indexes are stagnant, because the spatial integration of long-term residents is mitigated by higher segregation levels among new immigrants. Yet, segregation levels among these ethnic groups remain lower than those of the Afro-American population.

Immigration alters the population in many aspects: demographic, spatial, political, cultural, and socio-economic. Frey admirably covers the first three elements of this list, but less well the last two. The general tone of the book is positive and optimistic. Like many other authors, Frey celebrates racial and ethnic diversity and anticipates the achievement of a new post-racial society. In his view, large cohorts of new immigrants are much needed, if only to prevent a decline in the labour force population. He believes that they will fully integrate and rapidly reach the mainstream productivity level, though the facts he describes and discusses speak the opposite. He recognizes that conflicts may arise between a growing young minority population and an aging white population over public resources. He further recognizes that racial segregation is still very important in the USA, which has implications on the quality of the education that minorities are receiving, and consequently on their future well-being. Frey recognizes that there are continuing sharp social and economic divides between the disadvantaged minority group members and the white population, and that the recent recession has exacerbated economic disparities between whites and minorities. Yet, he believes that America is on the cusp of great change, and that the (white) population will soon both embrace 
and nurture the diversity. Somehow, in light of these assertions, Frey's conclusion appears more like wishful thinking than an evidence-based deduction. Socio-economic inequalities between blacks and whites might have decreased to a certain extent since the early 1960s, but fifty years after the Civil Rights Laws, racial inequalities are nowadays still very prevalent. Yet, the former was a time when the State was socially more involved in the economy. Since Reagan's era, neoliberal policies and laissezfaire economics are on the rise in most of the Western world, and perhaps even more in the USA. Incidentally, economic inequalities are also on the rise. In the context of increasing fiscal austerity, deregulation, free trade, globalization, and outsourcing of manufacturing jobs, it is difficult to foresee how the needed political and economic actions necessary to reduce racial and ethnic differences in poverty can be put forward, and how less educated minorities can access better-paid and rewarding jobs. 